\title{
Mathematical Model of Fine Aggregate Granulometry Complying With ASTM C33
}

\author{
M.J. Pellegrini-Cervantes ${ }^{1}$, G.M.Arizmendi-Valdez ${ }^{1}$, H. Cortez-Rodriguez ${ }^{1}$, \\ M. Chinchillas-Chinchillas ${ }^{1}$, A. Castro-Beltran ${ }^{1}$, F.J.Baldenebro-Lopez ${ }^{1}$, H.J. \\ Peinado-Guevara ${ }^{1}$, O. Llanes Cardenas ${ }^{2}$, R. Beltran-Chacon ${ }^{3}$ \\ ${ }^{I}$ Facultad de Ingeniería Mochis, UAS - Universidad Autónoma de Sinaloa. Fuente de Poseidón y calle Ángel \\ Flores S/N, Los Mochis, Sinaloa C.P. 81223, México. \\ ${ }^{2}$ Instituto Politécnico Nacional, Centro Interdisciplinario de investigación para desarrollo integral regional \\ unidad Sinaloa, Boulevard Juan de Dios Batís Paredes 250, Guasave, Sinaloa. C.P. 81101, México. \\ ${ }^{3}$ Centro de Investigación en Materiales Avanzados, Física de Materiales, Miguel de Cervantes 120, Chihuahua, \\ Chihuahua. C.P. 31109, México. \\ *manuel.pellegrini@uas.edu.mx
}

\begin{abstract}
The granulometry of fine aggregates is a fundamental test for the production of quality concrete [1], for this reason the American Association of Materials Testing (ASTM) has created a standard where it shows a granulometric ideal curve (formed by an upper bound and a lower limit), mentioning that the fine aggregate used for the preparation of concrete must be within these limits [4].At present, there are many mathematical models that predict fine aggregate granulometry, but none of them conforms to ASTM specifications [5]. For this reason, the need to elaborate a mathematical model arises that doescomply with those specifications.In this paper, different mathematical models were analyzed and compared with the ASTM C-33 granulometric curve.An equation was also designed that predicts fine aggregate granulometry with a Maximum Aggregate Size (MAS) of $4.76 \mathrm{~mm}$ and meets the requirements of ASTM C-33.
\end{abstract}

Keywords: - Granulometry, particle size, sands, aggregates.

\section{INTRODUCTION}

Aggregates are inert granular materials formed by fragments of rock or sand used in construction and in many industrial applications. Colloquially they are known as sand, gravel, grit, among others [1]. Aggregates in concrete constitute approximately 56 to $81 \%$ of the total volume, they do not intervene in the processes of hydration of the cement, they provide mechanical resistance, have good adhesion with cement paste, are used as filler material and they control volumetric changes of the cement paste avoiding the generation of cracks $[2,3]$. Due to their contributions, one of the characteristics that are most taken care of at the time of elaborating concrete is the size of the aggregates, for that reason, the American Association of Testing of Materials (ASTM) created the norm "Standard Specification for Concrete Aggregates "(ASTM C-33) where they propose a granulometric curve for the fine aggregate formed by a lower bound and an upper limit [4]. The test consists of passing a sample through graduated meshes and determining the percentage of material that is retained in each of them. The test results are graphed, the sieve opening against the percentage retained on each sieve to obtain a granulometric curve. If this curve is within the limits set by ASTM C-33, the fine aggregate is suitable for its use in concrete [5]. Another form to estimate the granulometry of fine aggregates commonly used is through mathematical models [6]. Many researches have been developed to predict granulometry, most of which are based on the arrangement, compaction of particles in a given volume [7, 8], on the form and origin of the aggregates, in order to achieve the maximum density and with this the maximum resistance $[9,10,11]$. The most widely used mathematical models for the prediction of aggregate granulometry are Fuller-Thompson, Weymounth, Sánchez de Guzman and Bolomey $[12,13]$. However, these mathematical models do not meet the granulometric limits set by ASTM C-33. Therefore, it is important to design a mathematical model that allows to obtain a granulometric curve that is within the quality parameters of ASTM.In this paper, a mathematical model is proposed that has the purpose to predict the granulometry of aggregates knowing the maximum size of aggregate to obtain a granulometric curve that is within the limits set by ASTM C-33 norm. 


\section{EXPERIMENTAL PROCEDURE}

\subsection{Study of mathematical models to obtain the granulometry}

Four existing mathematical models were analyzed to obtain the curve of the fine aggregates with different maximum sizes of aggregates (MAS), in order to know if the granulometric curve of these models, comply with the limits proposed in ASTM C-33 norm.

The first mathematical model analyzed was that of Fuller-Thomson, in which it is obtained the percentage that passes through the sieve with the formula that is observed in equation 1 , where the "d" represents the opening of the sieve, the "D" the MAS and the exponent is raised to $1 / 2$. This method produces rough and unmanageable blends in plastic state.

$$
P=100\left(\frac{d}{D}\right)^{1 / 2}
$$

The following method was Weymouth's method using equation 2, and it is based on that the fine particles of a single size must have enough space to move between the big particles and is based on the FullerThomson equation, changing the exponent of $1 / 2$ to " $n$ ", which governs the distribution of the particles and is in function of the coarse aggregate. For the case of the fine aggregate, the size d smaller than $4.76 \mathrm{~mm}$ will have a $\mathrm{n}$ of 0.305

$$
P=100\left(\frac{d}{D}\right)^{n}
$$

In practice, it was observed that increasing the value of $\mathrm{n}$ causes that more compaction energy is needed to achieve a unit MAS and a maximum resistance. That is why it is necessary to use values of $\mathrm{n}$ lower than 5.The next method analyzed was that of Sánchez de Guzmán, which adds to its expression a value of $\mathrm{n}$ of 0.45 to eliminate roughness, improves maneuverability and provides high resistances to obtain the ideal gradation curve, shown in equation 3.Based on the curve of the compressive strength (unit weight of concrete) against the value of $n$.

$$
P=100\left(\frac{d}{D}\right)^{0.45}
$$

Finally, is found the expression proposed by Bolomey, because it contemplates a higher content of fines within the MAS of the aggregate to improve the resistance of the mixture in plastic state and is the one that is currently more valid.Equation 4 shows the formula for obtaining the gradation curve, where constant $\mathrm{f}$ excels, which indicates the degree of workability of a mixture for a consistency and certain shape.

$$
P=f+(100-f)\left(\frac{d}{D}\right)^{0.5}
$$

In these models, the percentage of fines passed by No. 4 ", 8", 16 ", 30", 50 "and 100" mesh was calculated, where it was proposed to pass $100 \%$ aggregate in the first 4 meshes, graphing the results.

\subsection{Comparison of mathematical models with ASTM C-33.}

To make the comparison, the grain size limits established by ASTM C-33 were graphed, the values were obtained from this norm and on the same graph were placed the gradation curves of each mathematical model with different MAS. In order to know the behavior of each mathematical model and observe whether or not they comply with the limits of ASTM C-33.

\subsection{Proposed mathematical model.}

A proposal was made for a mathematical model that shows a granulometric curve within the limits of ASTM C-33, in which MAS of $4.76 \mathrm{~mm}$ was used. Since in practice and in laboratory tests, this is the maximum size of the average aggregate, which is why it is of great importance to find the exact equation to obtain the ideal curve with this aggregate size.

\section{RESULTS AND DISCUSSIONS}

\subsection{Obtaining the granulometry of existing mathematical models Fuller-Thomson}

Figure 1 shows the grain size curves for different maximum aggregate sizes (MAS) obtained using the mathematical model of Fuller-Thompson, in which MAS is used as its variable.The red curve and the strong blue mark the upper and lower limit of granulometry in ASTM C-33 norm. The orange and light blue line (MAS of 0.63 and $1 \mathrm{~mm}$ ) clearly show that they do not meet the grain size of ASTM norm, therefore, the mathematical model of Fuller would not comply with these two MAS.On the other hand, when MAS is $3 \mathrm{~mm}$, it can be observed that one part of the curve is out $(0.15$ and $0.5 \mathrm{~mm}$ sieve aperture) and the other within the limits set by ASTM (sieve aperture of $0.63,1$ and $3 \mathrm{~mm}$ ). And, finally, when MAS is $4.76 \mathrm{~mm}$, only two points in the graph 
are within ASTM granulometry and these are the retained percentage of the sand with a size of $0.63 \mathrm{~mm}$ and $4.76 \mathrm{~mm}$. The other points are not inside. Therefore, the mathematical model presented by Fuller does not show a granulometry suitable for the elaboration of concretes according to the regulations of ASTM.

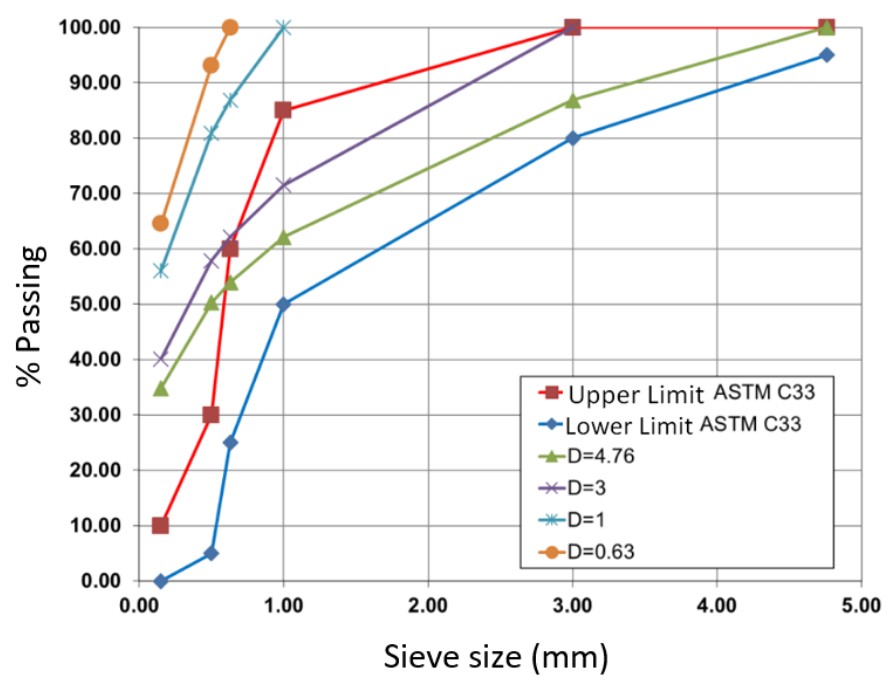

Figure 1.Granulometry of the Fuller-Thomson model with different MAS and ASTM C-33 limits.

\section{Weymounth}

The results of this mathematical model are observable in Figure 2.The difference of these results with those mentioned above is due to the change of the exponent in the formula, since Weymounth assigns a specific value of $n$ for each MAS.The graph shows that the grain size for a MAS aggregate of 0.63 and $1 \mathrm{~mm}$ does not comply with the limits set by ASTM C-33 norm. On the other hand, when MAS is $3 \mathrm{~mm}$, only two points in the graph corresponding to the opening of the sieve of 1 and $3 \mathrm{~mm}$ are within limits marked in the norm, the other points do not comply with this granulometry. The interesting thing is that when MAS is 4.76, the majority of the percentages retained in the meshes are within the lower and upper limits marked in ASTM C-33, only the smaller aggregates do not comply having a variation of approximately $20 \%$. It is worth mentioning that, in constructive practice, the most used MAS isof $4.76 \mathrm{~mm}$.

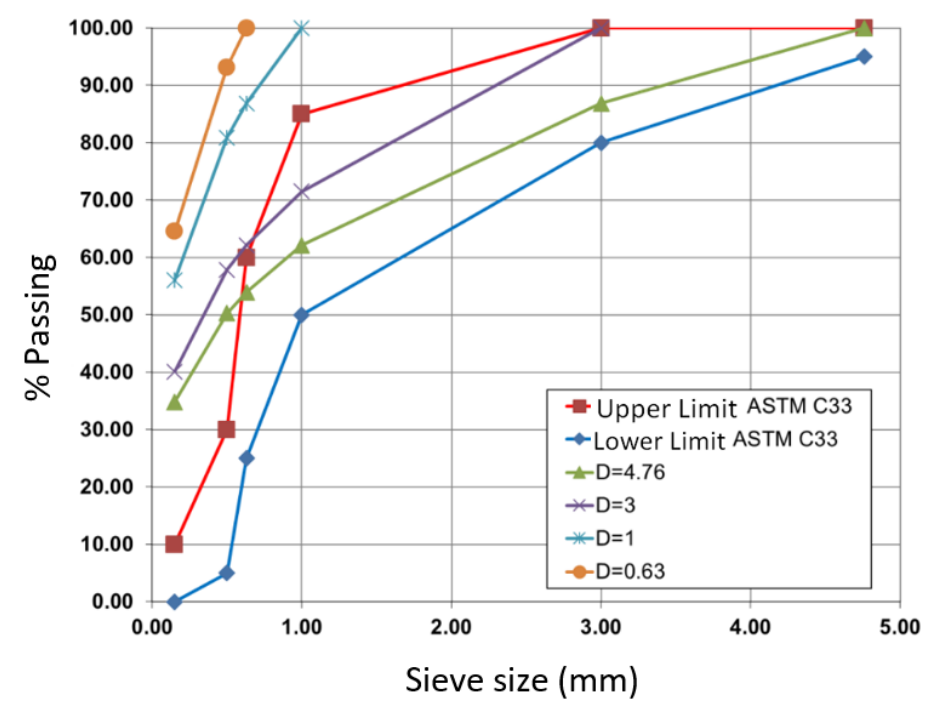

Figure 2.Granulometry of the Weymouth model with different MAS and ASTM C-33 limits. 


\section{Sánchez de Guzmán}

The results of graphing different MAS with the mathematical model of Sánchez de Guzmán are shown in Figure 3, where it is observed that the granulometry for MAS of 0.63 and $1 \mathrm{~mm}$, are not within the limits marked in the ASMT C-33 norm.For these sizes, Sánchez model would not comply. In the case of MAS of 3 $\mathrm{mm}$, three points of the graph comply with the limits that ASTM marks, being those of $0.63,1$ and $3 \mathrm{~mm}$. But the smaller sizes that are 0.15 and $0.5 \mathrm{~mm}$ do not comply.Finally, the particle size for a $4.76 \mathrm{~mm}$ MAS is very close to the lower limit of ASTM C-33, where the sizes of 4.76, 3 and $0.63 \mathrm{~mm}$ are within the limits of the norm, but the sizes of $3,0.5$ and $0.15 \mathrm{~mm}$ are not, staying out. Which tells us that this mathematical model is not suitable for the granulometryof the sand used in the elaboration of concrete with the specifications that marks ASMT C-33 norm.

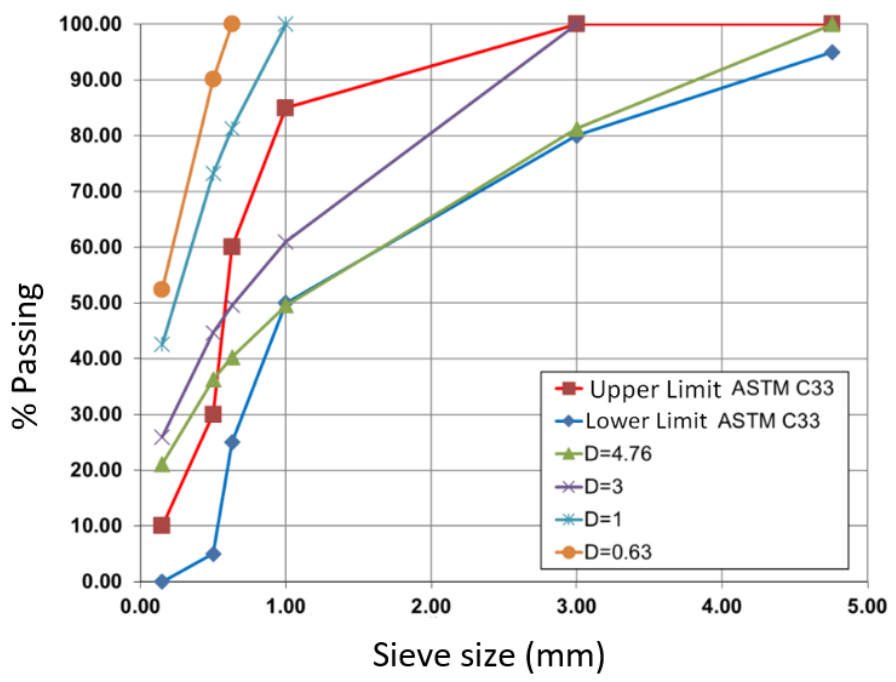

Figure 3.Granulometry of the Sánchez de Guzmán model with different MAS and ASTM C-33 limits.

\section{Bolomey}

The Bolomey model uses a factor $\mathrm{f}$, which can have different values depending on the shape of the aggregates and the consistency of the concrete in plastic state.Figure 4 shows the gradation curves of different MAS obtained from the Bolomey formula with a factor of 7, 10 and 12, taking into account that the shape of the aggregates is round and each graph corresponds to a state of consistency, dry, normal and plastic (respectively).As can be seen in the three figures, MAS of 0.63 and $1 \mathrm{~mm}$ do not meet the granulometry of ASTM C-33 norm.For a $3 \mathrm{~mm}$ MAS, the tendency is similar in all three graphs, only three points are within the norm $(3,1$ and 0.63$)$ and the smaller aggregate sizes are left out $(0.15$ and 0.5$)$. For a $4.76 \mathrm{~mm}$ MAS, as the "f" factor increases, the gradation curve within the limits set by according to ASTM norm. 

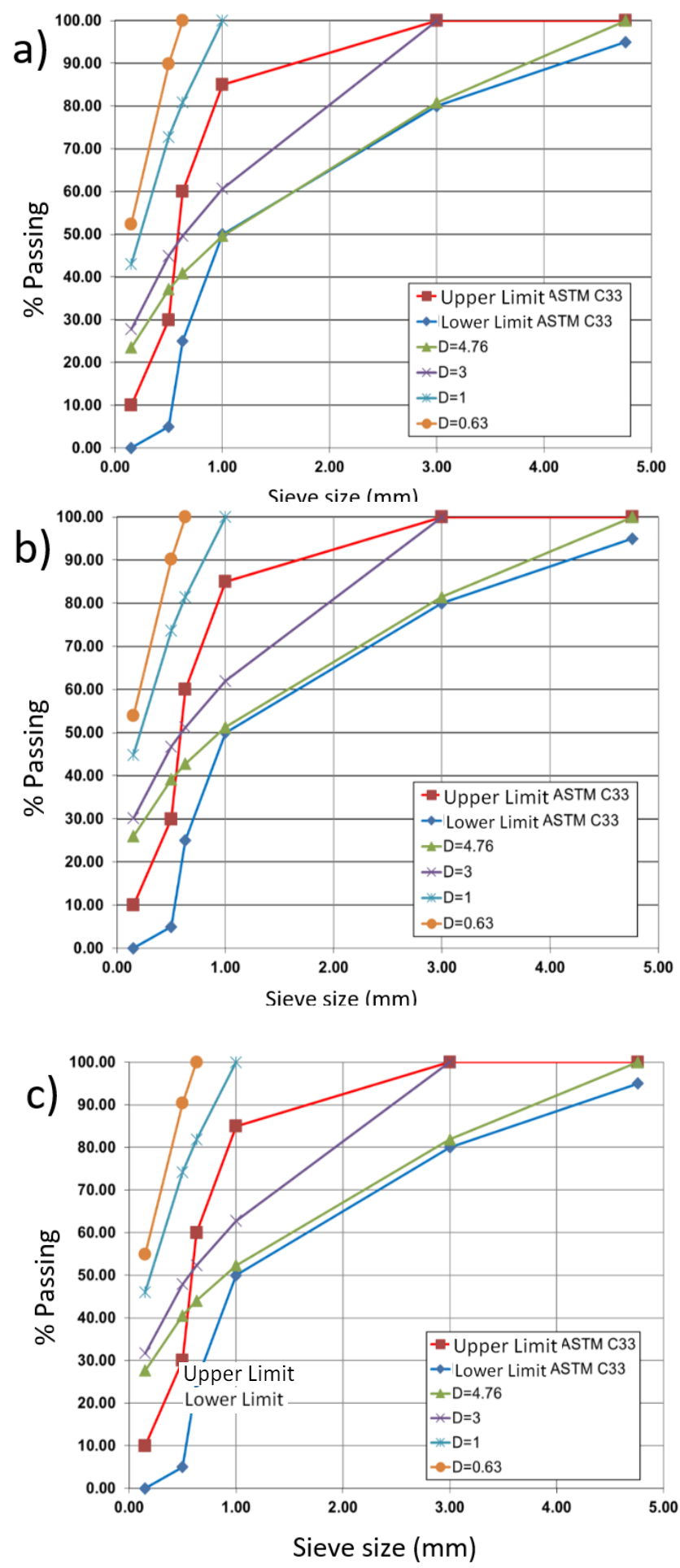

Figure 4.Granulometry of the Bolomey model with different $\mathrm{f}$ [a) of 7, b) of 10 and c) of 12] with different MAS and ASTM C-33 limits. 


\subsection{Obtaining the proposed mathematical model.}

In equation 5, it is observed the obtained formula, which uses as variables the maximum aggregate size (D) and the sieve aperture (d).The equation has three expressions, one of which contains an exponent raised to the third power, followed by the subtraction of another part raised to the square, followed by addition and subtraction.Substituting the sieve aperture and assuming that MAS is $4.76 \mathrm{~mm}$, the percentages that pass in each mesh would be obtained, obtaining the granulometric curve.

$$
\% \text { passing }=431.01\left[\frac{d}{D}\right]^{3}-581.45\left[\frac{d}{D}\right]^{2}+358.88\left[\frac{d}{D}\right]-3.44(5)
$$

3.3 Granulometry of the proposed mathematical model against granulometric limits of ASTM C-33 norm.

In Figure 5, it can be seen that using the proposed equation, shows a degradation curve that is within the granulometric limits set by ASTM C-33 norm. All points comply with the granulometry. In mesh No. 4, the percentage that passes is of $100 \%$ in mesh number 8 , the percentage of fine aggregate passing is of $99.68 \%$.In the next mesh, No. 16, the value of the percentage that passes is very close to the lower limit that marks the norm, but ends up staying within the limits with a 50.3\% that passes.Mesh No. 30 has the value of $34.9 \%$, mesh No. 50 has a percentage that passes 28.34 and the last mesh (No. 100) passes only $7.3 \%$. Where it is demonstrated that using the proposed equation with a $4.76 \mathrm{~mm}$ MAS produces a degradation curve suitable for its use, following the quality standards set by ASTM C-33 norm.

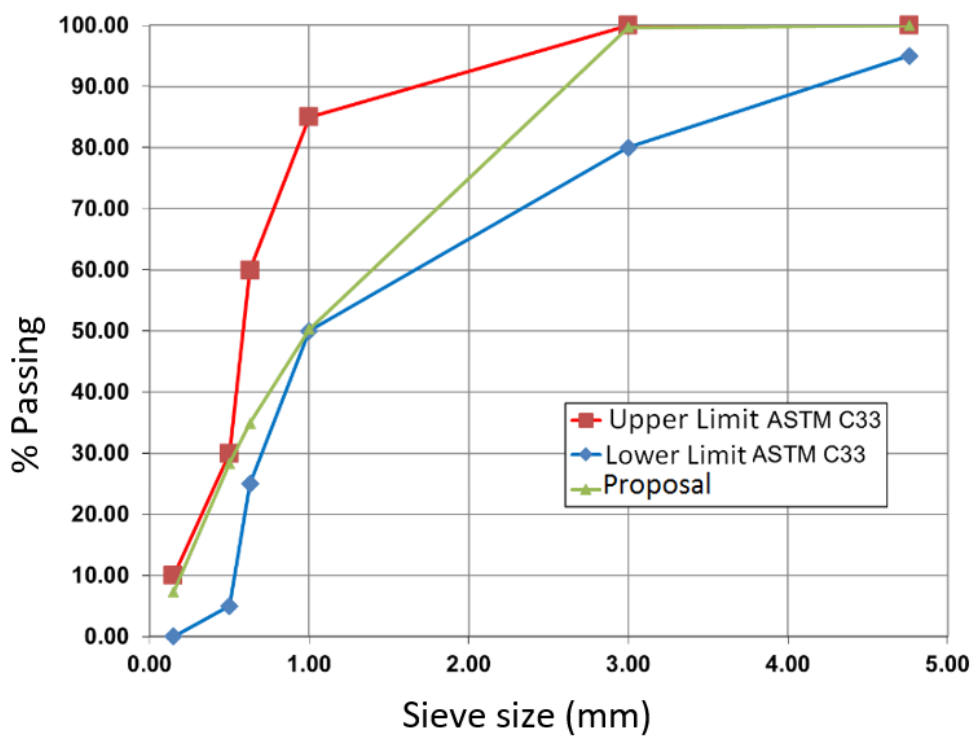

Figure 5.Granulometry of the proposed mathematical model with MAS of 4.76 and the granulometric limits of ASTM C-33 norm.

\section{CONCLUTION}

It was found that when using the mathematical models of Fuller-Thompson, Weymounth, Sánchez de Guzmán and Bolomey to obtain the granulometry of the sand with different MAS's, do not comply with the granulometric limits that mark ASTM C-33 norm, which is a very important specification to be able to use the fine aggregate in the elaboration of concretes. Consequently, these mathematical models cannot be used in the construction industry. It was possible to elaborate a mathematical model that serves to obtain an ideal granulometry according to ASTM C-33 norm for a MAS of $4.76 \mathrm{~mm}$. When using this model, a granulometry is obtained that is within the limits established by the norm and, therefore, the fine aggregate can be used for the elaboration of concrete. 


\section{ACKNOWLEDGEMENTS}

The authors thank the Autonomous University of Sinaloa, Faculty of Engineering Mochis for providing the facilities and equipment to carry out the research; to Dr. Manuel de JesúsPellegrini Cervantes for instructing us with his ample and successful teachings and to CONACyT for providing us a scholarship being viable the realization of it.

\section{REFERENCES}

[1] E. Martinez Conesa, C. Parra, P. Ortega, M. Valcuende, and I. Miñano, "Optimización del esqueleto granular.," 2012.

[2] Maria Patricia León, Fernando Ramirez. "Caracterización morfológica de agregados para concreto mediante el análisis de imágenes", 2010.

[3] M. Martinez Zamora, Lisandra; Torres Fuentes, "Límites de conformidad de finos pasados por el tamiz 200. Influencia reológico- mecánica en la matriz del hormigón.," vol. 7, no. 3, p. 79, 2013.

[4] I.E. Martínez-Soto y C.J. Mendoza-Escobedo. "Comportamiento mecánico de concreto fabricado con agregados reciclados", 2006.

[5] Jose Simeon Cañas. "Analisis de tamaño de partículas por tamizado en agregado fino y grueso y determinación de material más fino que el tamiz no. 200 (75 um) en agregado mineral por lavado",

[6] Libia Gutiérrez de López. "El concreto y otrosmaterialespara la construcción", 2003.

[7] Pablo GarcíaTriñanes. "Avances en aglomeración y compactación de partículas", 2010.

[8] E. Sangsefidi, H. Ziari, and M. Sangsefidi, "The Effect of Aggregate Gradation Limits Consideration on Performance Properties and Mixture Design Parameters of Hot Mix Asphalt," vol. 0, no. 0, pp. 1-8, 2015.

[9] A. Acosta Cazal , R. D. Cabrera Jara , A. Medina Acosta. "Influencia de la forma y la textura de los agregadosgruesos en laspropiedades del hormigón".

[10] José Toirac Corral. "El suelo-cementocomo material de construcción",2008.

[11] Y. Xiao, L. Chen, Z. Zhang, D. Lyu, E. Tutumluer, and J. Zhang, "Laboratory validation of a gradation design concept for sustainable applications of unbound granular materials in pavement construction," Constr. Build. Mater., pp. 1-15, 2016.

[12] J.D. Osorio Redondo. Tecnología del concreto-Tomo 1.Materiales, propiedades y diseños de mezclas.Terceraedicion. 2010.

[13] P. Taylor, J. Xu, and P. Hao, "Road Materials and Pavement Design Study of aggregate gradations in foamed bitumen mixes," no. February 2013, pp. 37-41, 2012. 